\title{
Parentalidade e gênero em famílias homoparentais francesas*
}

\author{
Flávio Luiz Tarnovski**
}

\section{Resumo}

As famílias formadas por gays e lésbicas têm se tornado progressivamente mais numerosas e visíveis em vários países do mundo ocidental. Na França, pais e mães homossexuais estão em sua grande maioria organizados em associações, sendo a APGL a principal delas. As famílias homoparentais francesas são oriundas de recomposições familiares, adoções, reprodução assistida ou coparentalidades. Este último caso, objeto deste artigo, se caracteriza por acordos entre gays e lésbicas para a procriação de crianças que circularão entre as residências paterna e materna. Argumento que, apesar da relativa novidade histórica dos arranjos de coparentalidade, as relações entre pais e mães reproduzem assimetrias de gênero que, no entanto, não possuem o mesmo significado que nas famílias constituídas por casais heterossexuais.

Palavras-chave: Paternidade, Maternidade, Homossexualidade, Homoparentalidade, Gênero.

\footnotetext{
* Recebido para publicação em 19 de janeiro de 2011, aceito em 5 de março de 2012. ** Professor adjunto do Departamento de Antropologia da Universidade Federal de Mato Grosso, Cuiabá-MT. flaviolt@gmail.com
}

cadernos pagu (40), janeiro-junho de 2013:67-93. 
Parentalidade e gênero em famílias homoparentais francesas

Parenthood and Gender in Gay and Lesbian French Families

\begin{abstract}
The families formed by gay men and lesbians have become increasingly numerous and visible in many countries of the Western world. In France, gay fathers and mothers are mostly organized in associations, with the APGL as the main one. The French same-sex families are derived from family reconstitution after divorce, adoptions, assisted reproduction or co-parenting. The latter case, the object of this article, characterizes arrangements made by gays and lesbians to have children who move between the paternal and maternal homes. I argue that despite the relative historical novelty of the co-parenting arrangements, the relationships between fathers and mothers continues to reproduce gender differences that, however, do not have the same meaning as in the families composed by heterosexual couples.
\end{abstract}

Key Words: Fatherhood, Motherhood, Homosexuality, Gay Parents, Gender. 
A partir de um trabalho de campo etnográfico realizado com pais homossexuais franceses para minha tese de doutorado em antropologia social, pretendo analisar as concepções de paternidade e maternidade atualizadas nesse contexto particular, caracterizado pela dissociação da sexualidade, da procriação e da parentalidade (Cadoret, 2002; Tarnovski, 2010). Na atualidade, as familias homoparentais podem ser consideradas como reveladoras das tensões que atravessam os campos da sexualidade e do parentesco (Schneider, 1997; Fonseca, 2008). Na França contemporânea, um número crescente de gays e lésbicas encontra na coparentalidade uma alternativa para a satisfação do desejo de ter filhos. Tais arranjos consistem em acordos para a procriação $e$ a criação alternada de crianças que circulam, desde o nascimento, entre as residências paterna e materna. Apesar do caráter inovador dessas configurações familiares, mostrarei como as concepções nativas de paternidade e maternidade continuam atualizando definições de gênero produtoras de assimetrias $e$ desigualdades. ${ }^{1}$ A pesquisa que fundamenta as análises foi realizada entre janeiro de 2006 e junho de 2008 e apoia-se em entrevistas aprofundadas com 23 pais homossexuais franceses $e$ em observações de seminários de estudos da associação de pais gays e mães lésbicas de Paris, de reuniões de um grupo de pais homossexuais divorciados e de outro de pais homossexuais adotivos. Dos homens entrevistados, 15 tornaram-se pais através de projetos de coparentalidade. ${ }^{2}$

\footnotetext{
1 Agradeço a Agnès Fine, orientadora da tese, pelas contribuições e críticas ao presente trabalho. Uma primeira versão deste texto foi apresentada no Seminário Internacional Fazendo Gênero 9 e posteriormente discutida com aluna(o)s da disciplina Seminários Temáticos sobre Gênero, do DICH/UFSC, ministrada pelas professoras Mara Lago e Miriam P. Grossi. Agradeço pelos comentários e sugestões recebidos nessas diferentes ocasiões. A pesquisa de doutorado contou com o apoio da Capes/Ministério da Educação.

2 Para efeitos de clareza da análise, o uso do termo "pais", no plural, será reservado para designar apenas os homens.
} 
Parentalidade e gênero em famílias homoparentais francesas

\section{A emergência das famílias homoparentais no contexto francês}

A visibilidade das famílias formadas por homossexuais na França está diretamente relacionada com a importância social $e$ política adquirida pela APGL (Association des Parents et futurs parents Gays et Lesbiens). Criada no início dos anos 80, essa associação congregava inicialmente homens $e$ mulheres divorciados e com filhos que passaram a se assumir como homossexuais. Progressivamente, mais mulheres passaram a integrar a associação, a ponto de serem maioria nos dias atuais. ${ }^{3}$ Também é possível constatar uma mudança nas modalidades de acesso à parentalidade: a prevalência inicial de homens $e$ mulheres divorciados deu lugar a uma maior preponderância de pais e mães adotivos ou que tiveram seus filhos através da utilização de novas tecnologias reprodutivas, ou ainda, que tiveram filhos entre si, através de projetos parentais elaborados no interior da associação. Esta última situação, sobre a qual centrarei minhas análises, é chamada de coparentalidade. Trata-se de arranjos familiares criados por gays e lésbicas ${ }^{4}$ que se associam com um parceiro do outro sexo para procriar, com ou sem relações sexuais, e criar a criança assim gerada em situações variadas de residência alternada. A coparentalidade pode assumir múltiplas formas de acordo com o status conjugal dos parceiros $e$ com o papel reservado a cada um dos atores envolvidos na elaboração do projeto. Assim, podemos ter situações em que um casal de homens decide ter uma criança com um casal de mulheres, um casal de mulheres com um homem solteiro (que pode se apresentar como homossexual ou heterossexual) ou ainda

3 De acordo com as estatísticas fornecidas pela APGL, a associação contava, em 1998, 255 homens (35\%) e 473 mulheres (65\%); em 2002, 401 homens (28\%) e 1033 mulheres (72\%); e em 2006, 458 homens (28\%) e 1153 mulheres (72\%).

4 As categorias "homossexual", "gay" e "lésbica" serão utilizadas indistintamente, conforme o uso feito pelos sujeitos da pesquisa. Para uma discussão sobre a genealogia histórica dessas noções, ver Foucault (1994). 
um casal de homens com uma mulher solteira (que também pode se apresentar como homossexual ou heterossexual).

$\mathrm{Na}$ França, a coparentalidade se tornou o meio mais comum de acesso à parentalidade para homens gays. Considerando-se que a adoção por indivíduos solteiros, embora prevista na lei, é de difícil concretização em função dos obstáculos interpostos pelas administrações quando há suspeição de que o candidato é homossexual, e que o acesso à maternidade de substituição é ilegal na França e de alto custo se realizado no exterior, a coparentalidade surge como a alternativa mais promissora para a satisfação do desejo de terem filhos. A lei, nesses casos, não lhes impõe qualquer restrição, visto que se enquadram na situação de casais fecundos em união livre. Dito de outro modo, através da coparentalidade, não precisam pedir autorização para serem pais nem encontram barreiras para o reconhecimento da filiação. As mulheres, por sua vez, têm seus filhos principalmente através de inseminações artificiais realizadas com esperma de doadores anônimos (Descoutures, 2010). Tais procedimentos são realizados em clínicas da Bélgica, da Holanda ou da Espanha. Muito embora os casais de mulheres não consigam estabelecer duplos vínculos de filiação com as crianças, podem concretizar seus projetos parentais sem terem que entrar em relação com homens. A recíproca não é verdadeira. No caso dos homens, mesmo quando buscam o auxílio de gestantes pagas, estabelecem relação com mulheres, pois elas são agentes ativas na concretização do projeto parental (e não apenas doadoras anônimas de substâncias corporais). ${ }^{5}$

$\mathrm{O}$ indivíduo ou o casal que deseja realizar uma coparentalidade pode encontrar possíveis parceiro(a)s em anúncios publicados em sites especializados ou no jornal interno

5 Em alguns casos, como os que analiso em minha tese de doutorado, casais de homens que buscam o serviço de mães substitutas norte-americanas se relacionam não só com as mulheres em questão, mas com suas respectivas famílias. Ver também Luna (2002) e Delaisi de Parseval e Collard (2007). 
da APGL ou ainda em reuniões de convivência organizadas por membros da associação. Neste último caso, a escolha dos parceiros não exclui formas de sedução que, no entanto, são esvaziadas de qualquer finalidade erótica (Tarnovski, 2011).

Após a escolha dos parceiros, são discutidos aspectos práticos relacionados com a procriação (Quem serão os genitores? Como realizarão a inseminação?) e com a organização familiar (Que posição ocuparão os parceiros não-genitores? Que nome e sobrenome terá a criança? Como será o compartilhamento da criança entre os parceiros? etc.). Frequentemente, as questões debatidas nessa fase de elaboração do projeto parental são materializadas num acordo formal e escrito que, apesar de não ter valor jurídico, traduz a vontade das partes e os termos do acordo que estabeleceram. Para tanto, as pessoas interessadas em realizar uma coparentalidade encontram na APGL modelos de contratos ou acordos (charte) formulados a partir da experiência acumulada por membros da associação (Gross e Peyceré, 2005). Como veremos adiante, o projeto inicial e a realidade das relações entre parceiros podem apresentar variações consideráveis e imprevistas após o nascimento da(s) criança(s), podendo levar a disputas, carregadas de emoção, que contrastam fortemente com os critérios "racionais" que pautaram a elaboração conjunta do projeto.

\section{A escolha da coparentalidade: “dar" um pai e uma mãe para a criança}

Dentre as motivações apontadas pelos pais e mães em coparentalidade para justificar a escolha desse arranjo familiar, a ideia de que a criança "deve" ter um pai e uma mãe aparece em destaque. Mesmo que se considere que para muitos homens a coparentalidade é a única alternativa que possuem para serem pais, essa "escolha" conforta igualmente um discurso social fortemente ancorado em teorias psicológicas vulgarizadas que insistem na necessidade das crianças terem um pai e uma mãe ou, segundo algumas correntes, "referências" masculinas e femininas 
(Mehl, 2003). Cabe notar que, no interior desse discurso, as referências masculinas e femininas só são consideradas eficazes se alocadas em homens e mulheres, respectivamente, indicando uma justaposição entre sexo e gênero.

A coparentalidade permite igualmente, ao contrário da adoção, que exista um "vínculo biológico" com a criança, que se traduz na expressão "enfant de ma propre chair". Por fim, a alternância de residências entre o polo materno e o polo paterno é também apresentada pelos homens como um aspecto positivo da coparentalidade, na medida em que o compartilhamento das responsabilidades parentais lhes permite desfrutar de tempo livre para outras atividades (trabalho, lazer, etc.). Como pretendo demonstrar, esses três pontos, uma representação generificada da parentalidade, uma concepção biogenética do parentesco (Schneider, 1980) e a prática comum de partilha das crianças são potencialmente geradoras de conflitos entre o(a)s parceiro(a)s da coparentalidade por serem abertos a interpretações divergentes.

\section{O gênero da parentalidade ou... de quem é a criança?}

Em contraste com o princípio de igualdade formal entre as filiações paterna e materna no contexto francês, na prática persistem assimetrias informadas por normas sociais e definições culturais de gênero. Em situações de divórcio, por exemplo, a residência principal das crianças é em sua grande maioria a das mães (Lefevre e Filhon, 2005). De uma maneira geral, essa situação de desigualdade face à responsabilidade parental $e$ ao cuidado infantil é associada com uma carga maior de trabalho doméstico feminino e com dificuldades de inserção profissional das mulheres (Guillot e Neyrand, 1993). No entanto, no contexto das famílias homoparentais, essa tendência geral à "matricentralidade" (Cadolle, 2007) pode ser responsável por uma inversão do valor atribuído à assimetria entre homens e mulheres. Em outras palavras, no caso específico das coparentalidades entre gays $e$ lésbicas, são os homens que se queixam de desigualdades 
Parentalidade e gênero em famílias homoparentais francesas

associadas ao gênero. Nesse sentido, tais formas familiares parecem inverter a lógica prevalecente nas famílias recompostas, categoria utilizada para designar os arranjos familiares resultantes da separação de casais heterossexuais com filhos.

$\mathrm{Na}$ sua forma, as famílias coparentais se assemelham às famílias recompostas em muitos aspectos, mas apresentam uma diferença fundamental: nas primeiras, as crianças são geradas para circular entre polos parentais que não guardam a memória de uma união conjugal. Idealmente, os arranjos coparentais seriam orientados por um conjunto de valores que, fundados na "escolha" e no "acordo", estariam livres dos conflitos associados ao descasamento (Théry, 2001). A observação de arranjos coparentais concretos parece indicar, ao contrário, uma quase tendência estrutural ao conflito.

André, 31 anos, professor, tem um filho em comum com um casal de mulheres. ${ }^{6}$ Desde o princípio, sua visão da coparentalidade pautou-se pelo ideal de uma partilha igualitária do tempo passado com a criança. Mas, já logo após o nascimento, surgiram desentendimentos relacionados com a importância atribuída ao aleitamento pela mãe legal e "biológica". A companheira da mãe, que também tinha pretensões de ocupar uma posição materna, encontrava-se, da mesma forma que o pai, em situação de desvantagem. Até entrarem num acordo quanto ao fim do aleitamento, que ocorreu após o primeiro semestre, o pai não pode ter seu filho longe do olhar materno por mais do que algumas horas. Passado esse período, novas tensões surgiram em razão das dificuldades encontradas por André para ter seu filho sem que a mãe e a companheira estivessem presentes. Um novo acordo foi estabelecido após o terceiro aniversário da criança, o que fez André abandonar sua intenção de recorrer à justiça.

Essa dificuldade de investimento paterno nos primeiros meses das crianças relaciona-se, igualmente, com representações negativas sobre as competências masculinas referentes aos

6 Os nomes dos sujeitos participantes da pesquisa são fictícios. 
cuidados na primeira infância. No caso de Eugène, 44 anos, professor, uma insegurança quanto às suas aptidões parentais ficou evidente no comportamento da mãe e da companheira dela. Quando traziam a criança para passar o final de semana com o pai, a cada quinze dias, as duas ficavam em um hotel nas proximidades de sua residência até o momento de retornarem para casa, a $130 \mathrm{~km}$ de distância, com a criança. Para Eugène, tratava-se de uma incapacidade manifesta da mãe de se afastar da filha e de uma desconfiança em relação às suas competências enquanto pai. A desconfiança materna terminou por se materializar em um processo judicial, no qual ela acusava Eugène de maus tratos à filha. Sem provas para sustentar a acusação, a decisão judicial garantiu o direito paterno de visitas. Tais fatos contrastam fortemente com as imagens projetadas por Eugène no momento de elaboração do projeto de coparentalidade. Para ele, diferentemente do que acontece entre os casais heterossexuais, a ausência de "amor" entre os parceiros seria uma garantia de serenidade: "eu pensava que nós nunca poderíamos nos detestar, pois nunca nos havíamos amado. Que grande engano, porque na realidade nós fizemos mais do que nos detestar".

Uma das causas subjacentes aos conflitos que emergem nessas situações está relacionada com as expectativas divergentes de cada polo da coparentalidade. De maneira recorrente, é possível identificar no polo materno um projeto de casal, no qual a criança teria uma função simbólica de confirmação do amor conjugal, ao passo que no polo paterno são mais frequentes as iniciativas individuais de homens com desejo de se tornarem pais. Mesmo quando possuem companheiros, estes ocupam uma posição inicial de "acompanhadores", investindo-se gradativamente em funções parentais após o nascimento da criança (Gross, 2006; Gratton, 2008). As diferenças no conteúdo dos respectivos projetos e a tendência à prevalência da posição materna, quando somadas, geram um sistema hierárquico no qual o pai e a companheira da mãe podem ser levados a disputar o lugar de "segundo(a)", depois da mãe "biológica" e legal (Gross, 
Parentalidade e gênero em famílias homoparentais francesas

2006). No caso de André, a disposição inicial em reconhecer a companheira da mãe como uma "mãe social" perdeu força depois dos conflitos gerados pela partilha do tempo com a criança. Considerando que a companheira da mãe não pode alicerçar suas revindicações sobre o compartilhamento de uma mesma substância, nem sobre um status legalmente reconhecido, só lhe resta o investimento no quotidiano doméstico e no desempenho de funções parentais como fundamento para o lugar que ocupa (Descoutures, 2010). Assim, no tempo passado com a criança está em jogo muito mais do que apenas o "prazer" com o desempenho de tarefas domésticas e educativas.

Nesse contexto, de capital escolar elevado, as negociações e disputas em torno das demandas de cada polo da coparentalidade mobilizam argumentos emprestados do universo científico para justificar os diferentes posicionamentos. Os homens e mulheres em coparentalidade se apropriam de noções da psicologia, cada um à sua maneira, com o objetivo de legitimar suas posições respectivas. Esse trecho de uma conversa entre um pai e uma mãe, a propósito do tempo suplementar reivindicado pelo primeiro para estar com a filha, e que me foi contada por seu companheiro, é um exemplo possível desse processo de apropriação:

A mãe dizia "escuta Bruno, eu tenho a impressão de ter uma segunda mamãe na minha frente quando tu falas assim. Isto desperta ciúmes em mim e eu não gosto que tu sejas assim porque eu tenho a impressão de ter uma segunda mãe na minha frente. $E$ então eu tenho a impressão de estar sendo despossuída de minha criança [...]". Resumindo, ela disse "comporte-se como um pai". Mas Bruno disse "sim, mas o pai está lá para cortar o vínculo (lien) entre a mãe e sua criança, papel que eu estou desempenhando", "sim, mas este não é o teu papel, mas o da minha companheira, que vive comigo no cotidiano $e$ que está lá para cortar o vínculo de fusão que tenho com minha filha", responde a mãe. Eu te deixo livre para interpretar depois... (Bernard) 
Nesse exemplo, vemos que a referência explícita ao discurso da psicologia pode ser uma maneira de legitimar (ou deslegitimar) as demandas de cada um dos parceiros parentais frente ao outro. Os dois parceiros não se encontram em uma relação simétrica e a preponderância da posição materna não é frontalmente posta em questão. A legitimidade da mãe em "possuir" (posséder) a criança não é questionada, mas sim a maneira como o faz. Em outra ocasião descrita por Bernard, a mãe teria insistido no sofrimento que lhe causava a perspectiva de se afastar da filha durante cinco dias para realizar uma viagem de trabalho. A verbalização desse sofrimento pode ser interpretada como uma maneira de dissuadir o pai e seu companheiro de suas reivindicações por mais tempo com a criança.

De acordo com Emmanuel Gratton, as "apropriações" de crianças por parte do pai são geralmente assimiladas a formas de violência contra as prerrogativas maternas (Gratton, 2008). A noção de "apropriação", nesse contexto, parece só ter sentido em relação ao comportamento paterno, na medida em que o laço materno aparece como uma evidência. Em outras palavras, tudo se passa como se a criança não "pertencesse" ao pai verdadeiramente, ou não da mesma maneira como "pertence" à mãe. Paradoxalmente, nesse contexto particular caracterizado por uma disposição paterna de implicação no cuidado e na educação das crianças, os pais defrontam-se muitas vezes com mães que não hesitam em evocar concepções essencialistas de maternidade para manter as assimetrias que, em outros contextos, têm sido fortemente questionadas (Guillot e Neyrand, 1993).

\section{Da boa distância no exercício da paternidade: entre o doador conhecido e o pai dedicado}

Em alguns casos, as disputas entre pais e mães têm origem numa provável discordância, geralmente não explicitada, quanto às motivações que os fizeram escolher a coparentalidade. Nesse sentido, é interessante notar que os arranjos coparentais assumem 
Parentalidade e gênero em famílias homoparentais francesas

configurações distintas em outros contextos nacionais - mas de forte presença de famílias constituídas por gays e lésbicas -, como Inglaterra, Estados Unidos ou, mais recentemente, Espanha (González e López, 2006; Lewin, 2009). Na literatura anglófona relacionada ao estudo de mães lésbicas, por exemplo, os genitores, mesmo quando conhecidos e desempenhando o papel de pais, são recorrentemente caracterizados como "doadores" (known donor). Os homens, nessas situações, permanecem num lugar de exterioridade em relação ao núcleo doméstico, e às vezes familiar, da criança (Hayden, 1995; Donovan, 2000; Ryan-Flood, 2005). Isto parece indicar que, ao contrário das práticas de coparentalidade entre gays e lésbicas franceses, que valorizam a norma sexuada da parentalidade, em outros países é a conjugalidade que aparece em primeiro plano. Assim, a criança pode até ter um pai conhecido, mas "pertence" ao casal de mulheres. Algumas situações encontradas na pesquisa apontam para uma predisposição semelhante por parte das mulheres, mas que não é corroborada ou compreendida por parte dos homens. A situação vivida por Cristophe, 66 anos, professor aposentado, é exemplar, pois mostra quão dramáticas podem ser as consequências desses (des)encontros de homens e mulheres em busca da satisfação do desejo de terem filho(a)s.

Christophe se tornou pai pela primeira vez aos 34 anos, no interior de um casamento de aparências com uma colega de estudos. Na época, as possibilidades de realização de uma coparentalidade não eram as mesmas que nos dias atuais. Pelo menos não da mesma maneira, isto é, separando-se sexualidade, conjugalidade e parentalidade (Tarnovski, 2012b). Christophe viveu dois anos com sua esposa, até o momento da confirmação de uma gravidez. Ela então pediu o divórcio e tentou obter seu acordo em abandonar os direitos paternos de visita. Ele não concordou, desencadeando uma série de conflitos com sua exesposa. Christophe esteve entre os primeiros membros da APGL, associação de pais gays e mães lésbicas, e anos mais tarde, com a popularização de novos modos de acesso à filiação, como a 
coparentalidade, ele resolve ter mais dois filhos. Christophe conheceu as mães das crianças em reuniões de convivência entre membros da associação, algumas das quais organizadas na sua casa. Atualmente, Christophe cultiva relações amistosas com a mãe do primeiro filho, de 12 anos, Carla, que mora em outra cidade, a $700 \mathrm{~km}$ de distância. Ele visita o filho uma vez por mês. Já com Christine, mãe de um rapaz de 11 anos, as relações são mais conflituosas. Os mal-entendidos começaram no momento de nascimento da criança, quando ela pediu a Christophe para não reconhecer seu filho, o que lhe permitiria receber auxílios financeiros por parte do Estado. Quando a criança completou 5 anos, o pai realizou um procedimento de reconhecimento de paternidade, sem que a mãe fosse consultada. Tal situação gerou conflitos que os levaram à justiça. Christophe não pôde mais ver o filho, até recentemente, quando passaram a se encontrar em visitas controladas por assistentes sociais. O drama enfrentado, tanto por Christophe quanto por Christine, parece ser o resultado de um confronto de visões divergentes sobre o conteúdo e o significado da coparentalidade realizada pelos dois. Tudo leva a crer que Christine estava procurando apenas um doador conhecido e não um pai dedicado.

Tais conflitos, quando existem, acabam por se tornar públicos no âmbito da APGL. Em uma conversa informal com uma ex-presidente da associação, comentei que havia entrevistado Christophe. Fui prontamente advertido sobre a personalidade polêmica do meu interlocutor, acusado de ser o responsável pelos conflitos. Segundo a representante da associação, ele teria se oferecido como "doador" (de esperma) e posteriormente mudado de opinião quanto à natureza da sua implicação na vida das crianças. Na versão que me estava sendo contada, Christophe aparecia como uma figura exterior que estava rompendo o equilíbrio da família formada pelo casal de mulheres e seu filho. No entanto, a situação vivida por Christophe parece ser o resultado de incompreensões mútuas entre os parceiros da coparentalidade. 
Parentalidade e gênero em famílias homoparentais francesas

Em outros casos, os eventuais conflitos relacionados com a extensão da participação paterna na vida das crianças é consequência de mudanças de expectativas e comportamentos em relação ao que foi acordado no momento de discussão do projeto. Quando conheci Julien, 40 anos, funcionário de uma revista, ele aguardava ansioso o nascimento do seu filho. A coparentalidade que estava por se concretizar foi fruto de uma longa busca pela mãe ideal. Julien conheceu três mulheres, e fez tentativas infrutuosas de fecundação com duas delas, antes de encontrar a futura mãe de seu filho, Janette, através de um anúncio publicado em um site especializado na internet. Em menos de seis meses eles decidem realizar uma coparentalidade e materializam os termos do acordo em um documento formal, no qual estipulam: o nome e o sobrenome da criança, a relação de dependência para fins de declaração de imposto de renda, a divisão das despesas, a guarda da criança (com alternância nas festas religiosas e Natal), que a criança terá uma conta bancária, que ela não poderá sair do país sem o acordo do pai e da mãe, entre outras questões. $\mathrm{O}$ objetivo do documento, que possui valor legal limitado, é de materializar o "estado de espírito" dos parceiros da coparentalidade com relação ao acordo firmado. Ele atua igualmente como uma declaração de "boas intenções" dos futuros pai e mãe. Apesar do nível de detalhamento descrito por Julien, no momento da entrevista, antes de a criança nascer, ele já vislumbrava uma flexibilização dos termos negociados. Se sentindo cada vez mais entusiasmado com a ideia de ser pai à medida que a gravidez avançava, Julien se projetava ocupando um espaço bem maior do que o previsto na vida de Janette e da criança.

[...] sua mãe vai se mudar, sua futura mãe vai morar a uma rua daqui. Eu acho que isto facilitará as coisas, isto é, existe uma previsão de guarda que foi fixada pelo contrato, mas é apenas uma previsão e eu penso que seria bom que eu o visse um pouco mais [...] eu penso que eu gostaria de um jantar uma vez por semana com a sua mamãe e o bebê. Eu não sei, ir buscá-lo na escola, sei lá, mas ser um pouco mais 
presente ainda, mesmo pelo telefone, encontrar outros meios de se cruzar, de passar um tempo juntos, não sei, $e$ de ser mais presente do que o que está previsto no contrato.

- Vocês discutiram sobre isso?

- Eu penso que é algo que acontecerá... sim, eu discuti sobre isso, mas eu penso que é uma coisa que se ajeitará aos poucos.

A maneira como Julien vislumbra o seu futuro como pai mostra a fragilidade do modelo de uma coparentalidade fundada em critérios racionais, negociados de maneira definitiva antes do nascimento da(s) criança(s). Ao mesmo tempo, seu relato deixa transparecer uma certa ansiedade e insegurança com relação à maneira como "construirá" um vínculo com seu filho. Isso fica evidente quando descreve a maneira como conversava com o bebê ainda no ventre da mãe ou como, ao longo da gravidez, estudava atentamente um livro sobre o desenvolvimento fetal. $\mathrm{O}$ mais curioso é que sua leitura avançava de acordo com a progressão da gestação, a leitura dos capítulos sendo paralela às semanas de gravidez.

Relatos como o de Julien, para quem a paternidade aparece como uma experiência de profundo valor existencial, não foram a regra dentre os casos estudados. Alguns pais encontrados estavam satisfeitos com um papel mais distante, muito embora não menos significativo. O ex-companheiro de Julien, Jean, 43 anos, engenheiro, também se tornou pai através de uma coparentalidade. A criança, uma menina de 3 anos, vive a maior parte do tempo com a mãe e a companheira, que por sua vez também tem uma filha em uma coparentalidade com outro casal de homens. Jean afirma que o tempo que passa com a filha é dividido de maneira "equilibrada" com a mãe: cada um tem um dia inteiro do final de semana para passar com a criança. Isto é, no seu cálculo, o tempo que "conta" é o do lazer, das horas de folga, e não o tempo do trabalho, da rotina cotidiana. Antes de realizar a coparentalidade, Jean havia feito uma tentativa de 
Parentalidade e gênero em famílias homoparentais francesas

adoção. Mas, na etapa final do processo de habilitação, nas consultas com o psicólogo, percebeu que a dedicação que uma adoção exigiria iria de encontro com seus planos profissionais. Naquele momento, cuidar de uma criança em tempo integral abalaria seus planos de ascensão profissional. A coparentalidade surgiu então como uma alternativa mais adaptada aos seus projetos de vida, na medida em que o sistema de alternância dos domicílios da criança não comprometeria seus objetivos profissionais (Tarnovski, 2012b).

Um modelo de paternidade, em que o mais importante parece ser a transmissão do nome patronímico e a ocupação de um lugar relativamente distante, por vezes resumindo-se a uma função simbólica de reconhecimento das diferenças de gênero, parece ser compartilhado por uma parcela das mulheres que buscam a coparentalidade, mas também por parte de alguns homens. No entanto, esse mesmo modelo está na base das tensões que acompanham esse tipo de configuração familiar.

\section{Fundamentos "naturais" $e$ "sociais" da paternidade e da maternidade}

A maneira como pais gays e mães lésbicas interpretam os conflitos em torno da guarda das crianças, nos primeiros anos de suas vidas, é reveladora das concepções euro-americanas de paternidade e maternidade: se para as mulheres as demandas paternas são traduzidas em termos de "separação" em relação à criança, para os homens a resistência das mães é percebida como implicando uma impossibilidade de "construção" do vínculo paterno. A motivação de certas mulheres em buscar um doador de esperma, que aceite ocupar um lugar simbólico na vida das crianças, mas que não queira ser pai em tempo integral, indica igualmente uma referência a um modelo de paternidade cindido entre as figuras do genitor e do "pai social", figuras estas associadas a momentos e modos de implicação distintos. 
Desde os primórdios da disciplina, a literatura antropológica estabeleceu uma distinção entre o "genitor" e o "pater", permitindo uma separação entre os aspectos "biológicos" $e$ propriamente "sociais" da paternidade (Radcliffe-Brown e Forde, 1982). Mas a ideia de que a paternidade seria uma experiência antes social que natural não foi sempre sistematicamente aplicada à maternidade, uma e outra estando assim respectivamente associadas à cultura e à natureza (Ortner, 1972; Mathieu, 1977). Paralelamente, etnografias mais atentas às representações nativas sobre o processo de procriação (Weiner, 1983), muitas das quais analisando a procriação como processo (Beckerman e Valentine, 2002), demonstraram que a separação entre "paternidade biológica" e "paternidade social" não é realizada de maneira universal, encontrando-se particularmente enraizada na cultura euro-americana (Schneider, 1984; Strathern, 1995). Outras sociedades não pensam a gravidez nos termos de uma fecundação de uma substância feminina por uma substância masculina, atribuindo significações particulares à relação sexual $e$ às substâncias corporais, como o esperma, o sangue menstrual ou o leite materno (Godelier, 2004).

A especificidade do conceito ocidental de paternidade transparece de maneira nítida nos trabalhos reunidos por Stephen Beckerman e Paul Valentine (2002) que, a partir do estudo de sociedades indígenas das Terras Baixas, revelam a extensão de teorias nativas permitindo a existência de múltiplos genitores. Em muitas das sociedades estudadas, a fecundação não se resume a um momento preciso, traduzível em termos biológicos. A concepção é antes o resultado de um processo, através do qual o feto é fabricado por aportes sucessivos e cumulativos de esperma. Esse complexo de práticas e representações sobre a paternidade múltipla nos permite colocar em perspectiva o modelo ocidental de paternidade, que Beckerman e Valentine definem como "one sperm, one fertilization doctrine". Os artigos reunidos pelos autores fornecem elementos para o desenvolvimento de uma crítica específica ao modelo clássico de paternidade, 
Parentalidade e gênero em famílias homoparentais francesas

tradicionalmente utilizado pelos antropólogos, a partir da concepção europeia dominante, como reconhecimento social de um vínculo biológico. ${ }^{7}$

$\mathrm{Na}$ cultura euro-americana, o fato de só podermos ter um pai e uma mãe, considerados enquanto genitor e genitora, é geralmente tratado como uma evidência (Strathern, 1995). As regras de filiação influenciadas por essa cultura se definem justamente por uma norma de exclusividade, posto que fundadas em um "modelo genealógico" (Ouellette, 1998; Bamford e Leach, 2009). ${ }^{8}$ As teorias da paternidade múltipla põem em perspectiva a particularidade desse modelo. Nessas teorias, o que é valorizado não é a transmissão de uma identidade de substância, de maneira definitiva e irreversível no momento da fecundação, mas a fabricação da pessoa, na medida em que a "produção" do feto é considerada como uma etapa de um processo mais vasto (Lea, 2002).

É possível argumentar que essas teorias alternativas não concordam com o saber estabelecido pela ciência ocidental sobre a fisiologia da reprodução humana, o que indicaria um conhecimento "errôneo" da biologia na base dessas "crenças". Na realidade, o que está em questão não é em que medida certas teorias nativas "ignoram" o mecanismo da reprodução sexuada, o que durante anos alimentou o famoso virgin birth debate, ${ }^{9}$ mas até

7 Em um estudo sobre diferentes definições culturais de paternidade, Delaney (1986) faz uma distinção entre modelos "monogenéticos" e "duogenéticos" de procriação. Meu interesse aqui é de sublinhar como, mesmo no interior de uma representação "duogenética", os vínculos de paternidade e de maternidade não são pensados segundo uma mesma lógica.

8 Que certas sociedades possam "ignorar" as "leis da reprodução" e criar terminologias classificatórias de parentesco, designando mais de um homem como pai ou mais de uma mulher como mãe, não contradiz o núcleo das representações euro-americanas, a saber, que uma criança só tem um genitor e uma genitora.

9 Debate antigo da antropologia social inglesa, retomado por Edmund Leach (1966) em um célebre artigo sobre a pretensa ignorância da paternidade biológica por parte de algumas populações tribais, e que se seguiu durante as décadas subsequentes através da publicação de artigos e cartas na revista Man. 
que ponto nossa fé na biologia científica nos impede de perceber os valores culturais aos quais ela serve de veículo. $\mathrm{O}$ fato de que as noções culturais euro-americanas sobre os "fatos da vida", de acordo com a expressão de David Schneider (1980), possam em aparência corresponder ao saber acumulado pela biologia ou pela medicina nos torna cegos à especificidade dessas noções.

Mas, se por um lado, as definições ocidentais de parentesco associam-no com a procriação, de outro, os efeitos dessas representações sobre a paternidade $e$ a maternidade não são simétricos (Fine, 2001). Apesar da referência comum à "biologia", ou ao "sangue", em termos gerais a noção euro-americana de paternidade se distingue pela ênfase posta na ideia de "reconhecimento". A oposição genitor/pater, retomada pela antropologia para demonstrar o caráter social do parentesco (Radcliffe-Brown e Forde, 1982), supõe um ato voluntário de "reconhecimento", do qual a presunção de paternidade no interior do casamento nada mais é que a tradução jurídica. A maternidade, ao contrário, não é pensada segundo os mesmos termos, como se a passagem da genitrix à mater fosse automática. De acordo com esse conjunto de representações, o homem se tornaria pai ao reconhecer, a mulher ao dar à luz. Assim, o comportamento paterno não seria uma consequência do "vínculo biológico", mas derivaria da fé na existência deste vínculo, ao passo que o comportamento materno seria coextensivo à geração e ao parto (Fonseca, 2004). ${ }^{10}$ Nesse sentido, um "bom pai" é alguém que ocupa uma posição extraordinária, enquanto que uma "boa mãe" nada mais faz do que aquilo que se espera de uma mãe. O discurso contemporâneo sobre os "novos pais" reatualiza o paradigma da paternidade enquanto "reconhecimento social" e engajamento voluntário. É possível considerar que, se a

\footnotetext{
${ }^{10}$ No entanto, em certas situações, como a da maternidade de substituição associada com a doação de óvulos, essa relação de continuidade entre a concepção, o parto e a maternidade já não é mais tão óbvia. Ver Luna (2002) e Delaisi de Parseval e Collard (2007).
} 
Parentalidade e gênero em famílias homoparentais francesas

emergência dessa nova categoria de pais é digna de nota, é porque tal aparição acontece num contexto em que $\mathrm{o}$ investimento dos homens em tarefas domésticas (ainda) não é evidente, mas extraordinário (Oliveira, 1998).

O contraste entre concepções assimétricas de paternidade e maternidade aparece igualmente no debate francês sobre a "crise da filiação" (Laborde-Barbanegre, 1998). Uma das supostas causas dessa crise seria a introdução do critério de "verdade biológica" como referência para a determinação do vínculo jurídico de filiação. Ora, esse critério apenas se tornou problemático a partir do desenvolvimento de exames de DNA, ao permitirem a confirmação ou não de existência de "vínculos biológicos" de paternidade. Dessa forma, não é tanto a filiação em geral que estaria se "biologizando", mas antes a filiação paterna que estaria se tornando uma "realidade" demonstrável (Fonseca, 2004). O fato de que, na França, a filiação materna tenha se tornado, depois de julho de 2006, uma consequência automática do parto não mereceu a mesma atenção no interior desse debate. Nesse sentido, paternidade e maternidade parecem estar numa relação inversa no que tange ao campo de ação no qual homens $e$ mulheres podem manifestar sua vontade através do "reconhecimento" da filiação. O genitor, ao reconhecer sua paternidade, cria uma relação. No entanto, a genitora sendo automaticamente designada como mãe, tem o caráter voluntário do vínculo materno expresso apenas quando da recusa do seu estabelecimento. ${ }^{11}$ Uma mulher pode manifestar positivamente sua vontade de tornar-se mãe ao escolher ter um filho, mas a questão é justamente que ela seja considerada como "tornando-se mãe" ao gerar e parir uma criança.

\footnotetext{
${ }^{11} \mathrm{Na}$ França, a prática de nascimentos ditos "sous $x$ " permite que as mulheres possam dar à luz anonimamente. No entanto, na medida em que a identidade da genitora é apagada dos registros, o genitor da criança fica impossibilitado de estabelecer a filiação paterna.
} 
Essas concepções assimétricas indicam que os laços criados pela paternidade e pela maternidade não são situados em um mesmo nível, associando-se a duas noções distintas de relatedness (Carsten, 2000). Contrariamente ao laço criado pela paternidade, o vínculo materno é antes pensado como um "dado", na medida em que ele não é pensado como a consequência de um processo de "construção". O laço paterno, ao contrário, seria condicionado $e$ dependente de um investimento paterno, sendo portanto socialmente definido e percebido como um vínculo "construído". ${ }^{12}$ Essa visão se encontra traduzida, por exemplo, em certas teorias da psicologia, que caracterizam o laço mãe/filho(a) como "fusional" e o papel paterno como "separador". Para essas teorias, o vínculo mais significativo do pai não é com o(a) filho(a), mas com a mãe. ${ }^{13}$

As coparentalidades entre gays e lésbicas podem ser consideradas inovadoras na medida em que permitem dissociar a parentalidade da conjugalidade heterossexual. No entanto, o exercício da paternidade continua a ser determinado pela mediação das mães. Da mesma forma, a análise de situações concretas revela que mesmo dissociando-se sexualidade, procriação e conjugalidade, a parentalidade não é jamais neutra em relação ao gênero.

\section{Gênero, parentalidade e poder}

Para Emmanuel Gratton, "a coparentalidade se apresenta como a única via realista para certos gays se tornarem pais, ao passo que ela é antes uma escolha para as mulheres lésbicas"

\footnotetext{
${ }^{12}$ Para desenvolvimentos teóricos a respeito da oposição dado/construído, ver Wagner (1975) e Viveiros de Castro (2004).

${ }^{13}$ Estudos sobre a utilização dos testes de DNA revelam igualmente que, muitas vezes, o que está em jogo na busca de uma "prova" do "vínculo genético" de paternidade não é tanto o fortalecimento de uma concepção biogenética do parentesco, mas a confirmação da fidelidade das companheiras, mãe das crianças. Para maiores desenvolvimentos sobre esta questão ver Fonseca (2004).
} 
Parentalidade e gênero em famílias homoparentais francesas

(Gratton, 2008:208). O autor considera que as mulheres se encontram em posição de força e podem impor suas escolhas aos homens, contentes de poder encontrar uma parceira parental. Segundo Gratton, nesse contexto, a paternidade estaria submetida ao "poder (puissance) das mães". O autor se opõe assim a certas análises feministas, segundo as quais a maternidade seria um dos suportes da subordinação das mulheres, e a considera ao contrário como fonte de dominação. De acordo com minhas análises, a questão central que atravessa os conflitos entre homens $e$ mulheres em coparentalidade não parece ser tanto a da dominação, mas a das definições de gênero. Homens e mulheres mobilizam diferentes definições de paternidade e de maternidade nas suas visões da coparentalidade. Como mostra Martine Gross (2006), as mães lésbicas em coparentalidade querem "dar" um pai aos seus filhos, mas têm dificuldade em dar as crianças aos pais.

Os conflitos que podem resultar da coparentalidade entre gays e lésbicas, quando analisados do ponto de vista dos sujeitos, nos revelam que as relações de força entre homens e mulheres não possuem uma direção única e universal. Eles devem ser restituídos aos seus contextos para serem interpretados a partir dos sentidos atribuídos pelos agentes sociais. Percebemos assim que o gênero não é um atributo fixo, mas uma construção que se reatualiza na relação (Théry, 2007). As concepções de paternidade $e$ de maternidade mobilizadas pelos homens $e$ mulheres em coparentalidade mostram que as definições de gênero, ao mesmo tempo em que são informadas por modelos culturais e normas sociais, são igualmente apropriadas pelos sujeitos em função de suas posições no interior de quadros relacionais particulares.

No contexto preciso dos arranjos de coparentalidade, as mulheres podem mais facilmente impor suas próprias definições sobre o conteúdo dos papéis paterno e materno, o que poderia ser caracterizado como uma situação de empoderamento pela maternidade. No entanto, esse empoderamento é limitado. $\mathrm{Na}$ esfera profissional, por exemplo, a maternidade pode dificultar as oportunidades de ascensão na carreira (Berrebi-Hoffman et alii., 
2009). Ao mesmo tempo, os embates entre homens e mulheres em coparentalidade na França não podem ser dissociados do quadro social mais amplo no qual eles estão situados. As famílias encontradas durante a pesquisa fazem parte das camadas médias intelectualizadas com acesso a serviços de creches, babás e empregadas domésticas. A maioria das crianças encontrava na casa dos pais as mesmas condições que tinham na residência materna, isto é, um quarto próprio com móveis, roupas, etc. A parentalidade, nesse contexto social específico, parece estar muito mais relacionada à busca de satisfação pessoal do que ao cumprimento de tarefas domésticas repetitivas e cotidianas.

Concluindo, ao analisar as concepções de paternidade e de maternidade atualizadas nas configurações familiares coparentais realizadas por gays e lésbicas na França, foram identificadas tensões envolvendo as modalidades de compartilhamento das crianças entre os parceiros. Os pais e mães em disputa mobilizam definições de paternidade e de maternidade confirmadoras de assimetrias persistentes no campo da parentalidade. No entanto, tais definições não são apenas o reflexo de supostas "imposições" de modelos culturais e normas sociais, mas o resultado de apropriações realizadas pelos atores para legitimar suas posições em uma situação marcada por constantes renegociações quanto aos contornos e ao conteúdo da família.

\section{Referências bibliográficas}

BAMFORD, Sandra e LEACH, James. (orgs.) Kinship and beyond. The genealogical model reconsidered. Oxford, Berghahn, 2009.

BECKERMAN, Stephen e VAlENTINE, Paul. (orgs.) Cultures of multiple fathers. The theory and practice of partible paternity in Lowland South America. Gainesville, University Press of Florida, 2002.

BERREBI-HOFFMAN, Isabelle; LALLEMENT, Michel; NiCOLE-DRANCOURT, Chantal e SARFATI, François. Ambivalência, gênero e modernidade capitalista. Cadernos Pagu (32), Campinas-SP, Núcleo de Estudos de Gênero - Pagu/Unicamp, 2009, pp.9-42. 
Parentalidade e gênero em famílias homoparentais francesas

CADOLLE, Sylvie. La place du beau-père dans les familles recomposées: une paternité de substitution? In: SELLENET, Catherine. (org.) Les pères en débat. Ramonville Saint-Agne, Erès, 2007, pp.29-47.

CADORET, Anne. Des parents comme les autres. Homosexualité et parenté. Paris, Éditions Odile Jacob, 2002.

CARSTEN, Janet. (org.) Cultures of Relatedness: New Approaches to the Study of Kinship. Cambridge, Cambridge University Press, 2000.

DELAISI DE PARSEVAL, Geneviève e COLLARD, Chantal. La gestation pour autrui: un bricolage des représentations de la paternité et de la maternité euro-américaines. L'Homme (183), Paris, Éditions de L'E.H.E.S.S., 2007, pp.29-54.

DELANEY, Carol. The meaning of paternity in the virgin birth debate. Man, New Series, vol. 21, $\mathrm{n}^{\circ}$ 3, London, Royal Anthropological Institute of Great Britain and Ireland, 1986, pp.494-513.

DESCOUTURES, Virginie. Les mères lesbiennes. Paris, PUF, 2010.

DONOVAN, Catherine. Who needs a father? Negotiating biological fatherhood in British lesbian families using self-insemination. Sexualities, vol. 3, n² 2, London, Sage, 2000, pp.149-164.

FINE, Agnès. Maternité et identité féminine. In: KNIBIEHLER, Yvonne. (org.) Maternité, affaire privée, affaire publique. Paris, Bayard, 2001, pp.61-76.

FONSECA, Claudia. A certeza que pariu a dúvida: paternidade e DNA. Revista Estudos Feministas, vol. 12, n 2, CFH e CCE/UFSC, 2004, pp.13-34.

. Homoparentalidade: novas luzes sobre o parentesco. Revista Estudos Feministas, vol. 16, n 3, Florianópolis-SC, CFH e CCE/UFSC, 2008, pp.769-783.

FouCAult, Michel. Histoire de la sexualité. La volonté de savoir. Paris, Gallimard, 1994 [1976].

Godelier, Maurice. Métamorphoses de la parenté. Paris, Fayard, 2004.

GONZÁLEZ, María-Mar e López, Francisca. Qu'a-t-on appris des familles homoparentales en Espagne? In: Cadoret, Anne et alii. (orgs.) 
Homoparentalités. Approches scientifiques et politiques. Paris, PUF, 2006, pp.223-244.

GRATTON, Emmanuel. L'homoparentalité au masculin. Le désir d'enfant contre l'ordre social. Paris, Le monde/PUF, 2008.

Gross, Martine. Désir d'enfant chez les gays et les lesbiennes. Terrain (46), Paris, Ministère de la Culture, 2006, pp.151-164.

e PEYCERÉ, Mathieu. Fonder une famille homoparentale. Paris, Ramsay, 2005.

Guillot, Caroline e NEYRAND, Gérard. Le parent seul, l'enfant, la société. Autrement (134), Paris, Éditions Autrement, 1993, pp.50-61.

HAYDEN, Corinne P. Gender, genetics, and generation: reformulating biology in lesbian kinship. Cultural Anthropology, vol. 10, $\mathrm{n}^{\circ} 1$, Durham, Department of Cultural Anthropology/Duke University, 1995, pp.41-63.

LABORDE-BARBANEGRE, Michèle. La filiation en question. De la loi du 3 janvier 1972 aux lois sur la bioéthique. In: FINE, Agnès. (org.) Adoptions. Ethnologie des parentés choisies. Paris, Ed. de la Maison des Sciences de l'Homme, 1998, pp.177-204.

LEA, Vanessa. Multiple paternity among the Mebengokre (Kayapó, Jê) of central Brazil. In: BECKERMAN, Stephen e VALENTINE, Paul. (orgs.) Cultures of multiple fathers. Gainesville, University Press of Florida, 2002, pp.105-122.

LEACH, Edmund. Virgin Birth. Proceedings of the Royal anthropological Institute of Great Britain and Ireland, London, Royal anthropological Institute of Great Britain and Ireland, 1966, pp.39-49.

LEFEVRE, Cécilie e FILHON, Alexandra. (orgs.) Histoire de familles, histoires familiales. Les résultats de l'enquête Famille de 1999. Paris, Ined, 2005.

LEWIN, Ellen. Gay fatherhood: narratives of family and citizenship in America. Chicago, University of Chicago Press, 2009.

MATHIEU, Nicole-Claude. Paternité biologique, maternité sociale. In: MichEL, Andrée. (org.) Femmes, sexisme et sociétés. Paris, PUF, 1977, pp.39-48. 
Parentalidade e gênero em famílias homoparentais francesas

MEHL, Dominique. La bonne parole, quand les psys parlent dans les media. Paris, Ed. de La Martinière, 2003.

OliveirA, Pedro Paulo de. Discursos sobre a masculinidade. Revista Estudos Feministas, ano 6, $\mathrm{n}^{\circ}$ 1, Rio de Janeiro-RJ, IFCS/UFRJ, 1998, pp.91-112.

ORTNER, Sherry B. Is female to male as nature is to culture? Feminist Studies, vol. 1, n 2,1972 , pp.5-31.

OUELETTE, Françoise-Romaine. Les usages contemporains de l'adoption. In: FINE, Agnès. (org.) Adoptions. Ethnologie des parentés choisies. Paris, Editions de la Maison des Sciences de l'Homme, 1998, pp.153-176.

RADCLIFFE-Brown, Alfred R. e FORDE, C. Daryll. Sistemas Políticos Africanos de parentesco e casamento. Lisboa, Fundação Calouste Gulbekian, 1982 [1950].

RYAN-FLOOD, Róisín. Contested heteronormativities: discourses of fatherhood among lesbian parents in Sweden and Ireland. Sexualities, vol. 8, n², London, Sage, 2005, pp.189-204.

SCHNEIDER, David. The power of culture: notes on some aspects of gay and lesbian kinship in America today. Cultural Anthropology, vol. 12, $\mathrm{n}^{\circ}$ 2, Durham, Department of Cultural Anthropology/Duke University, 1997, pp.270-274.

. A critique of the study of kinship. Ann Arbor, University of Michigan Press, 1984.

American kinship. Chicago/London, University of Chicago Press, 1980 [1968].

STRATHERN, Marilyn. Necessidade de pais, necessidade de mães. Revista Estudos Feministas, ano 3, $n^{\circ} 2$, Rio de Janeiro-RJ, IFCS/UFRJ, 1995, pp.303-329.

TARNOVSKI, Flávio Luiz. Paternité et sexualité dans la construction de soi. Ethnologie française, vol. $42, \mathrm{n}^{\circ} 1$, Paris, Société d'ethnologie française/PUF, 2012a, pp.145-153.

. Devenir père homosexuel en France: la construction sociale du désir d'enfant. Etnográfica, vol. 16, n 2, Lisboa, CRIA, 2012b, pp.247-267. 
. Les coparentalités entre gays et lesbiennes en France: le point de vue des pères. Vibrant, vol. $8, \mathrm{n}^{\circ} 2$, Brasília-DF, Associação Brasileira de Antropologia, 2011, pp.140-163. Disponível em: http://www.vibrant.org.br/downloads/v8n2_tarnovski.pdf. Acesso em 03.01.2012.

. Être père et homosexuel dans la France contemporaine. Tese de Doutorado, Antropologia Social, EHESS (Toulouse), 2010.

THERY, Irène. La distinction de sexe. Paris, Odile Jacob, 2007. . Le démariage. Paris, Odile Jacob, 2001.

VIVEIROS DE CASTRO, Eduardo. Le don et le donné: trois nano-essais sur la parenté et la magie. Ethnographiques.org, n 6, 2004. Disponível em: $\quad$ <ttp://www.ethnographiques.org/2004/Viveiros-de-Castro>. Acesso em: 19.06.2009.

WAGneR, Roy. The invention of culture. Chicago, University of Chicago Press, 1975.

WEINER, Annette B. La richesse des femmes ou comment l'esprit vient aux hommes (Iles Trobriand). Paris, Seuil, 1983. 